\title{
PM7 Study on the Electronic Structure and Light Absorption of Some OPE (Oligo-Phenylene-Ethynylene Derivative)- $\mathrm{RE}_{3} \mathrm{~N} @ \mathrm{C}_{80}$ Dyads
}

\author{
Kye-Ryong Sin ${ }^{*}$, Sun-Gyong Ko, Yong-Min Jang, Hong-Gol O. \\ Department of Chemistry, Kim Il Sung University, Pyongyang, Democratic People's Republic of Korea
}

Email address:

ryongnam9@yahoo.com (Kye-Ryong Sin)

${ }^{*}$ Corresponding author

\section{To cite this article:}

Kye-Ryong Sin, Sun-Gyong Ko, Yong-Min Jang, Hong-Gol O. PM7 Study on the Electronic Structure and Light Absorption of Some OPE (Oligo-Phenylene-Ethynylene Derivative)-RE $\mathrm{R}_{3} \mathrm{~N} \mathrm{C}_{80}$ Dyads. Modern Chemistry. Vol. 5, No. 5, 2017, pp. 75-81. doi: $10.11648 /$ j.mc.20170505.11

Received: November 12, 2016; Accepted: December 27, 2016; Published: November 1, 2017

\begin{abstract}
In this paper, we investigated the electronic structure and stability of some mesomorphic OPE-RE $\mathrm{N} @ \mathrm{C}_{80}$ dyads from the oligo-phenylene-ethynylene derivatives (OPE) and the trimetallic nitride template endohedral fullerenes (TNT-EMFs) - $\mathrm{RE}_{3} \mathrm{~N} @ \mathrm{C}_{80}(\mathrm{RE}=\mathrm{Sc}, \mathrm{Y}, \mathrm{La})$ by using PM7, the updated version of the semi-empirical Hartree-Fock method. In OPE$\mathrm{RE}_{3} \mathrm{~N} @ \mathrm{C}_{80}$, the fullerene cages were modified to have the opened cage (fulleroid) structure by addition of OPE on the $[6,6]$ position of the fullerene cages. There was no considerable charge transfer between OPE and fullerene cage, but the fullerene cages had the remarkable minus charges mainly due to the electron transfer from $\mathrm{RE}_{3} \mathrm{~N}$ to the cage. The calculated electronic spectra showed that light absorption bands of OPE- $\mathrm{C}_{80}$ were more red-shifted than that of OPE-RE $\mathrm{E}_{3} \mathrm{~N} @ \mathrm{C}_{80}$ and all of OPE$\mathrm{RE}_{3} \mathrm{~N} @ \mathrm{C}_{80}$ seem to have a couple of Vis-NIR absorption peaks.
\end{abstract}

Keywords: Endohedral Fullerene, Oligo-Phenylene-Ethynylene Derivatives, TNT-EMF, Quantum Chemistry, PM7

\section{Introduction}

Now it is well-known that fullerenes are not chemically inert and undergo various chemical reactions such as nucleophilic addition, Diel's-Alder reaction, 1,3-dipolar cycloaddition, radical addition, oxidation, reduction etc. [1, $2,3]$ By chemical modifications of the fullerene cages there appeared a number of fullerene derivatives, which opened their potential application in practice. [4]

Many researches have been carried out for synthesis of the endohedral metallofullerenes (EMFs), the so-called "clusterfullerene", containing metal atoms or clusters therein and for their application in manufacture of the useful nano-materials such as molecular devices and molecular medicines. [5] From the first preparation of $\mathrm{La} @ \mathrm{C}_{82}$ in 1991, there made lots of advances in synthesis and application of the endohedral fullerenes with metal atoms or their nitride. [6]

Since the cluster fullerenes have peculiar properties useful in electronics, magnetics and photonics, they could enjoy the wider prosperity in many applications such as molecular electronics and bio-technology. [7, 8] The recent reports showed the possibility of control of the stability, reactivity, solubility and function of the endohedral fullerenes by adding some organic compound on their surfaces. [9]

Especially, a variety of the trimetallic nitride template endohedral fullerenes (TNT-EMFs) such as $\mathrm{RE}_{3} \mathrm{~N} @ \mathrm{C}_{\mathrm{n}}(\mathrm{RE}=$ Sc, Y, La; $\mathrm{n}=78,80,82, \cdots)$ have been synthesized and modified for utilizing their functionalities in molecular electronics and bio-technology.[10] One of the most prosperous applications of $\mathrm{RE}_{3} \mathrm{~N} @ \mathrm{C}_{\mathrm{n}}$ can be found in organic photovoltaics due to their excellent electron acceptor abilities. A recent research was carried out for synthesis of some $\pi$-conjugated system - fullerene dyads for photovoltaic applications, where the donor units were either oligophenylene-ethynylene (OPE) or oligo-phenylene-vinylene $(\mathrm{OPV})$ derivatives and for the acceptor, $\mathrm{C}_{60}$ or $\mathrm{Y}_{3} \mathrm{~N} @ \mathrm{C}_{80}$ were used.[11] The liquid crystalline behavior, shown by the synthesized dyads was expected to improve the photovoltaic efficiency of the BHJ (block hetero-junction) organic solar cells by ambipolar charge transfer. 
The rare earth elements (Sc, Y and lanthanides) have been attracting the interest of many research groups around the world due to their peculiar electronic, magnetic and biological characteristics including luminescence properties. Nowadays, increasing number of articles have been published every year on the synthesis of the functional materials containing the rare earth elements, but many of them could not be supported by the quantum chemical interpretation of their experimental results because of heavy cost of the theoretical computations. [12, 13]

To solve this problem, many researchers pay attention to MOPAC, the semi-empirical Hartree-Fock molecular orbital software package, which offers the most efficient quantum chemical calculations with the enhanced accuracy for a wide range of molecules, complexes, polymers, crystals, and TNTEMFs. [12, 14] Especially, MOPAC2016, the latest version of MOPAC, has PM7 method and the Sparkle Models for lanthanides, and has wide application with other quantum chemical softwares such as LUMPAC [15] for design and preparation of the new series of the rare earth luminescence materials and supramolecular devices. [16]

In this paper, PM7 in MOPAC2016 was applied in the theoretical study on the electronic structure and stability of OPE- $\mathrm{C}_{80}$ and OPE-RE 3 N@ $\mathrm{C}_{80}$ dyads $(\mathrm{RE}=\mathrm{Sc}, \mathrm{Y}, \mathrm{La})$. There have been some reports on DFT (Density Functional Theory) study on $\mathrm{RE}_{3} \mathrm{~N} @ \mathrm{C}_{\mathrm{n}}$ and their derivatives [5, 17], but still no research has been done on theoretical calculation of the electronic structures of the OPE- $\mathrm{RE}_{3} \mathrm{~N} @ \mathrm{C}_{80}$ dyads.

\section{Computational Models and Method}

Here the quantum chemical study has been done on four OPE-FD dyads (OPE- $\mathrm{C}_{80}$ and OPE-RE $\left.3 \mathrm{~N} @ \mathrm{C}_{80}\right)$, where FD means $\mathrm{C}_{80}$ and three kinds of $\mathrm{RE}_{3} \mathrm{~N} @ \mathrm{C}_{80}(\mathrm{RE}=\mathrm{Sc}, \mathrm{Y}, \mathrm{La})$.

For all the OPE-FDs, the geometry of $\mathrm{C}_{80}-\mathrm{I}_{\mathrm{h}}$, one of the geometric isomers of $\mathrm{C}_{80}$, was chosen as the fullerene cage, where $I_{h}$ shows the geometric symmetry of the fullerene cage. (Figure 1)
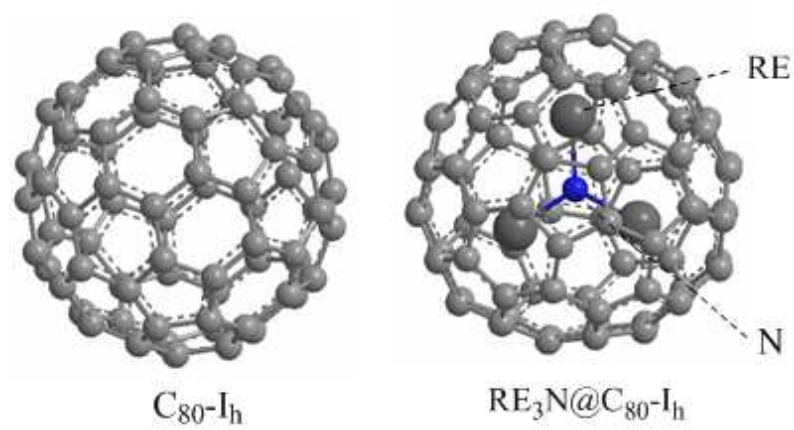

Figure 1. Models for FDs $(R E=S c, Y, L a)$.

Figure 2 shows the chemical structures of the OPE$\mathrm{Y}_{3} \mathrm{~N} @ \mathrm{C}_{80}$ dyad, synthesized in the previous research. [11] According to that experimental research, the models for OPE- $\mathrm{C}_{80}$ and OPE-RE $3 \mathrm{~N} @ \mathrm{C}_{80}$ dyad (RE=Sc, Y, La) were chosen as [6,6] adducts, where OPE was covalently linked to $\mathrm{C}_{80}$ or $\mathrm{RE}_{3} \mathrm{~N} @ \mathrm{C}_{80}$ just on the $[6,6]$ addition site of the fullerene cage (the nearest site to $\mathrm{RE}$ atom in case of $\left.\mathrm{RE}_{3} \mathrm{~N} @ \mathrm{C}_{80}\right)$. To simplify the task and avoid the overload in computation, the long alkyl chain $\mathrm{R}\left(-\mathrm{C}_{12} \mathrm{H}_{25}\right)$ in the OPE was shortened as $-\mathrm{CH}_{3}$ in all the models for OPE-FDs.

The OPE-FDs can be separated as two individual subunits, OPE and FD, for comparing their electron donor - acceptor interaction. Here $\mathrm{OPE}_{1}$ symbolizes a half part of OPE (Figure 3).
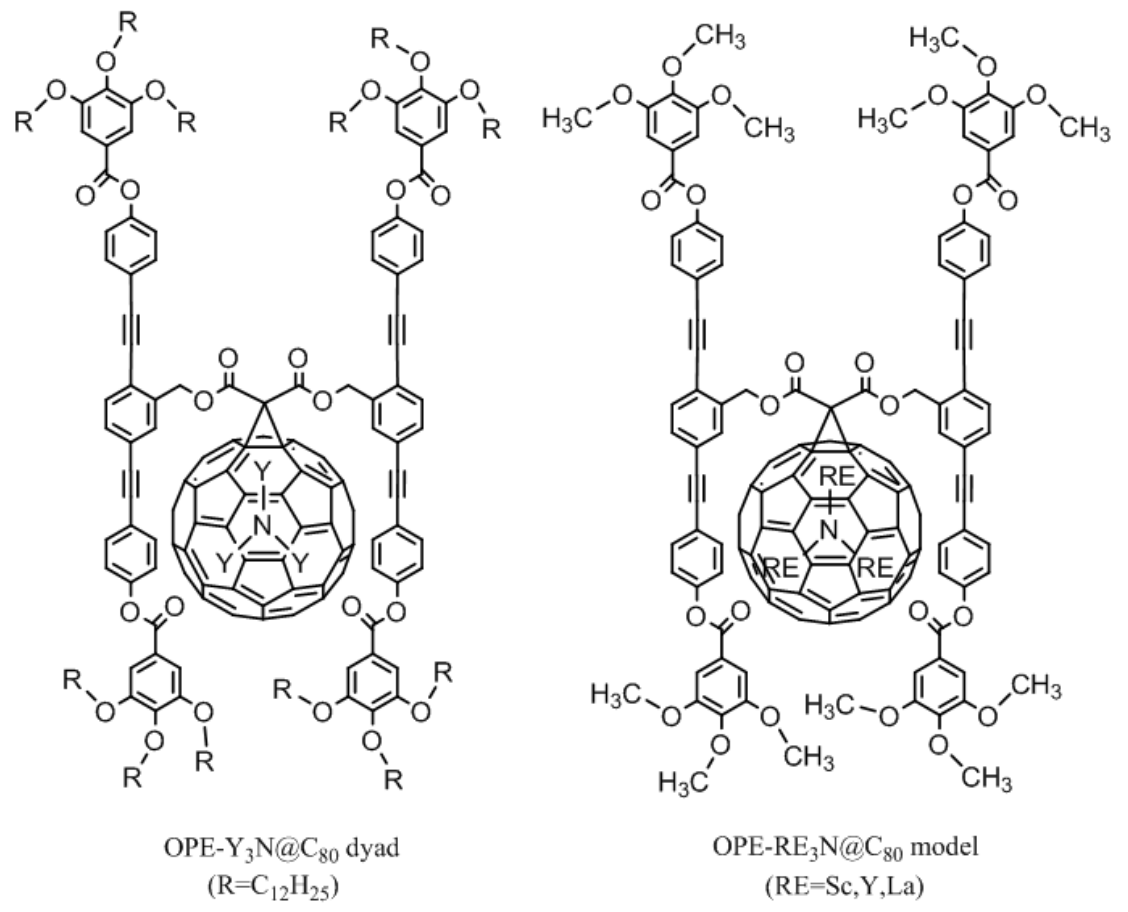

Figure 2. Models for OPE-FDs. 


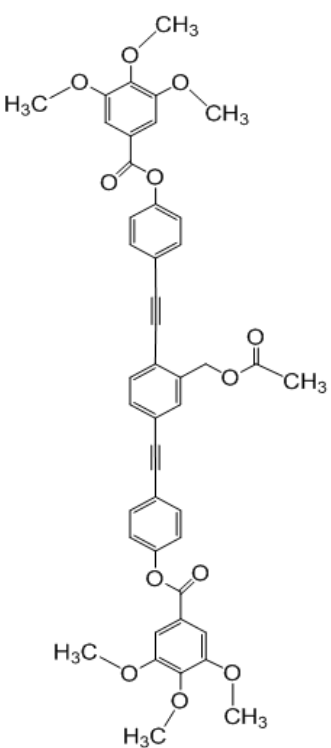

$\mathrm{OPE}_{1}$

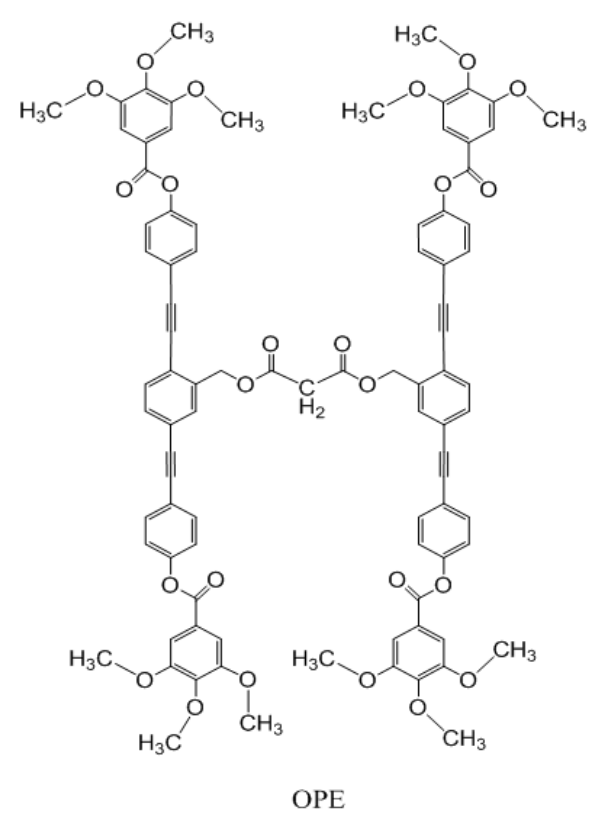

OPE

Figure 3. Models for $O P E$ and $O P E_{1}$.

To consider the effect of $\mathrm{RE}_{3} \mathrm{~N}$ on the electronic structure of the OPE- $-\mathrm{RE}_{3} \mathrm{~N} @ \mathrm{C}_{80}$, the empty fullerene cage model without $\mathrm{RE}_{3} \mathrm{~N}$ was also calculated as OPE- $\mathrm{C}_{80}$.

The geometric and electronic structures of the models were calculated by PM7 from MOPAC2016.

The first step of calculation was the geometry optimization by L-BFGS routine, which was followed by the configuration interaction $(\mathrm{CI})$ calculation based on the single-point $\mathrm{MO}$ results. The configurations for the singlet electronic transitions were composed of $20 \mathrm{MOs}$ near HOMO and LUMO (10 occupied MOs and 10 unoccupied MOs). The electronic spectra were drawn by using the Gaussian smoothing function based on the transition energies (mode positions) and the oscillator strengths (mode intensities).
Relative Stability of the OPE-FDs was evaluated by $\Delta \mathrm{E}_{\mathrm{t}}$, the difference of total energies $\left(\mathrm{E}_{\mathrm{t}}\right)$ between the resulting model (OPE-FD) and the separated subunits (OPE and FD).

\section{Results and Discussion}

1) The geometric and electronic structures of the separated subunits (OPE and FDs)

Figure 4 shows the optimized geometric structures of OPE and its one branch $\left(\mathrm{OPE}_{1}\right)$, where the phenylethynyl unit ($\mathrm{C}_{6} \mathrm{H}_{4}-\mathrm{C} \equiv \mathrm{C}-\mathrm{C}_{6} \mathrm{H}_{4}-\mathrm{C} \equiv \mathrm{C}-\mathrm{C}_{6} \mathrm{H}_{4}-$ ) is arranged to forms a straight line, but its three phenyl rings are not on the same plane, which prevents to form larger $\pi$-conjugation plane in OPE.
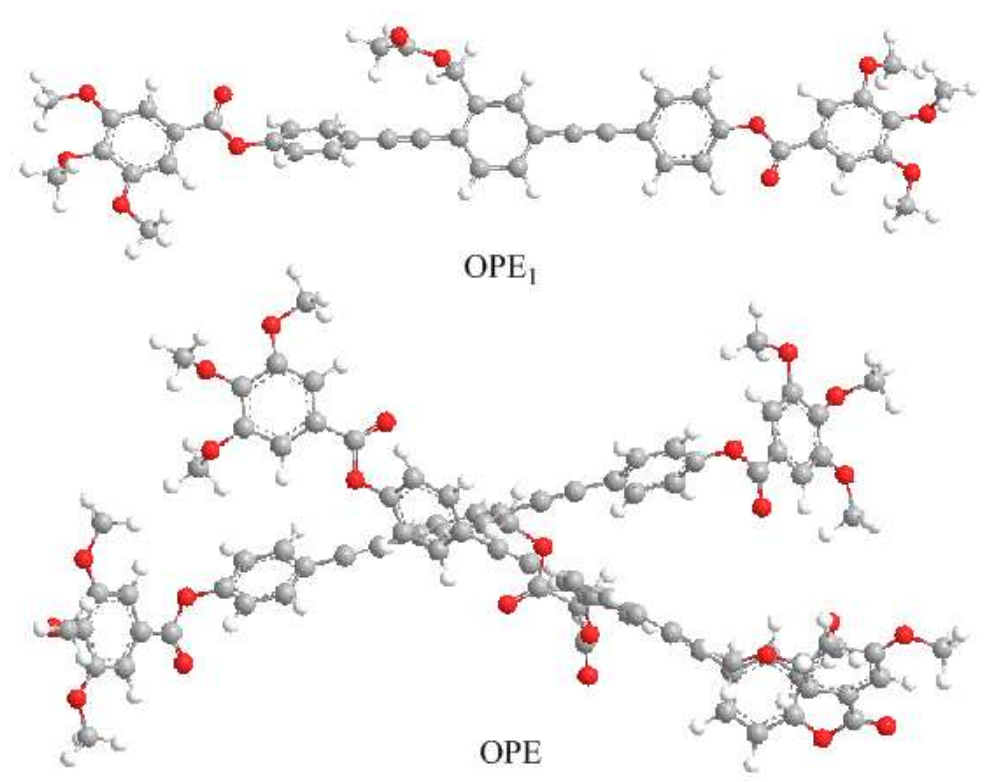

Figure 4. The optimized geometric structures of OPE and its one branch $\left(O P E_{1}\right)$. 
It can be seen from the optimized geometric structures of $\mathrm{RE}_{3} \mathrm{~N} @ \mathrm{C}_{80}$ in Figure 5 that $\mathrm{RE}_{3} \mathrm{~N}(\mathrm{RE}=\mathrm{Sc}, \mathrm{La})$ has the planar form, but $\mathrm{Y}_{3} \mathrm{~N}$ has the pyramidal form, which resembles the previous XRD measurement of $\mathrm{Gd}_{3} \mathrm{~N} @ \mathrm{C}_{80}-\mathrm{I}_{\mathrm{h}}$ and DFT calculation of $\mathrm{Y}_{3} \mathrm{~N} @ \mathrm{C}_{78}-\mathrm{D}_{3 \mathrm{~h}} \cdot[18,19]$

From the electronic structures of $\mathrm{RE}_{3} \mathrm{~N} @ \mathrm{C}_{80}$ calculated from their optimized geometry, it was found out that the positive charge of RE atoms was increased and the negative charge of $\mathrm{N}$ atom decreased in the cluster fullerene compared with those in free $\mathrm{RE}_{3} \mathrm{~N}$, which shows that in $\mathrm{RE}_{3} \mathrm{~N} @ \mathrm{C}_{80}$ more portion of electrons of RE atoms was transferred to the fullerene cage, not to $\mathrm{N}$ atom.

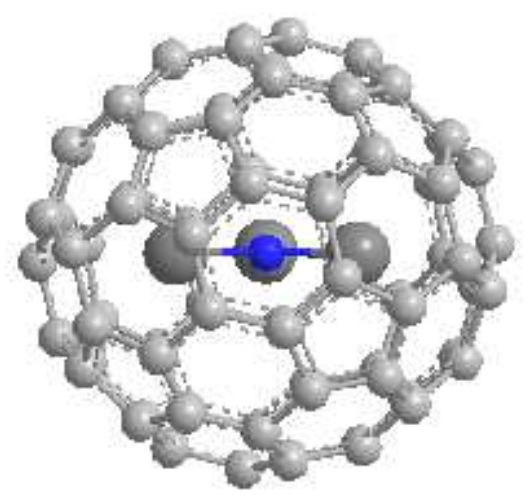

$\mathrm{Sc}_{3} \mathrm{~N} @ \mathrm{C}_{80}$

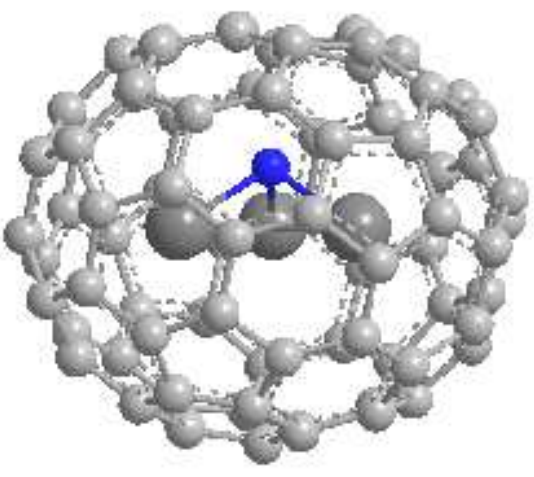

$\mathrm{Y}_{3} \mathrm{~N} @ \mathrm{C}_{80}$

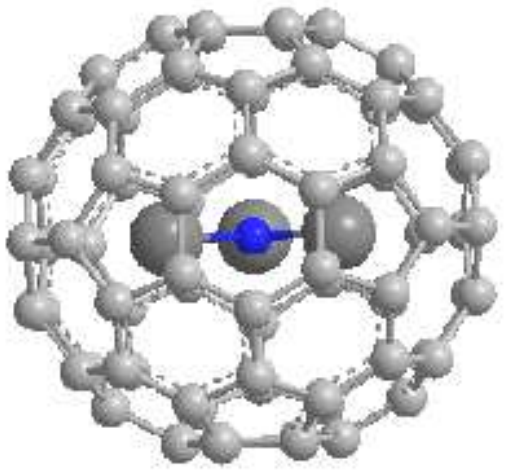

$\mathrm{La}_{3} \mathrm{~N} @ \mathrm{C}_{80}$

Figure 5. The optimized geometric structures of $R E_{3} N @ C_{80}$.

Figure 6 shows that $\mathrm{OPE}_{1}$ and $\mathrm{OPE}$ have the similar HOMO-LUMO levels, which means there can not be apparent $\pi$-conjugation between two phenylethynyl branches in OPE. All FDs $\left(\mathrm{C}_{80}\right.$ and $\left.\mathrm{RE}_{3} \mathrm{~N} @ \mathrm{C}_{80}\right)$ have lower LUMO levels than OPE, therefore they can accept electron from OPE. HOMO levels of $\mathrm{RE}_{3} \mathrm{~N} @ \mathrm{C}_{80}$ are lower than that of the empty $\mathrm{C}_{80}$. It can be explained as the result of stabilization of the $\mathrm{C}_{80}$ cage by $\mathrm{RE}_{3} \mathrm{~N}$ incorporation. [20]

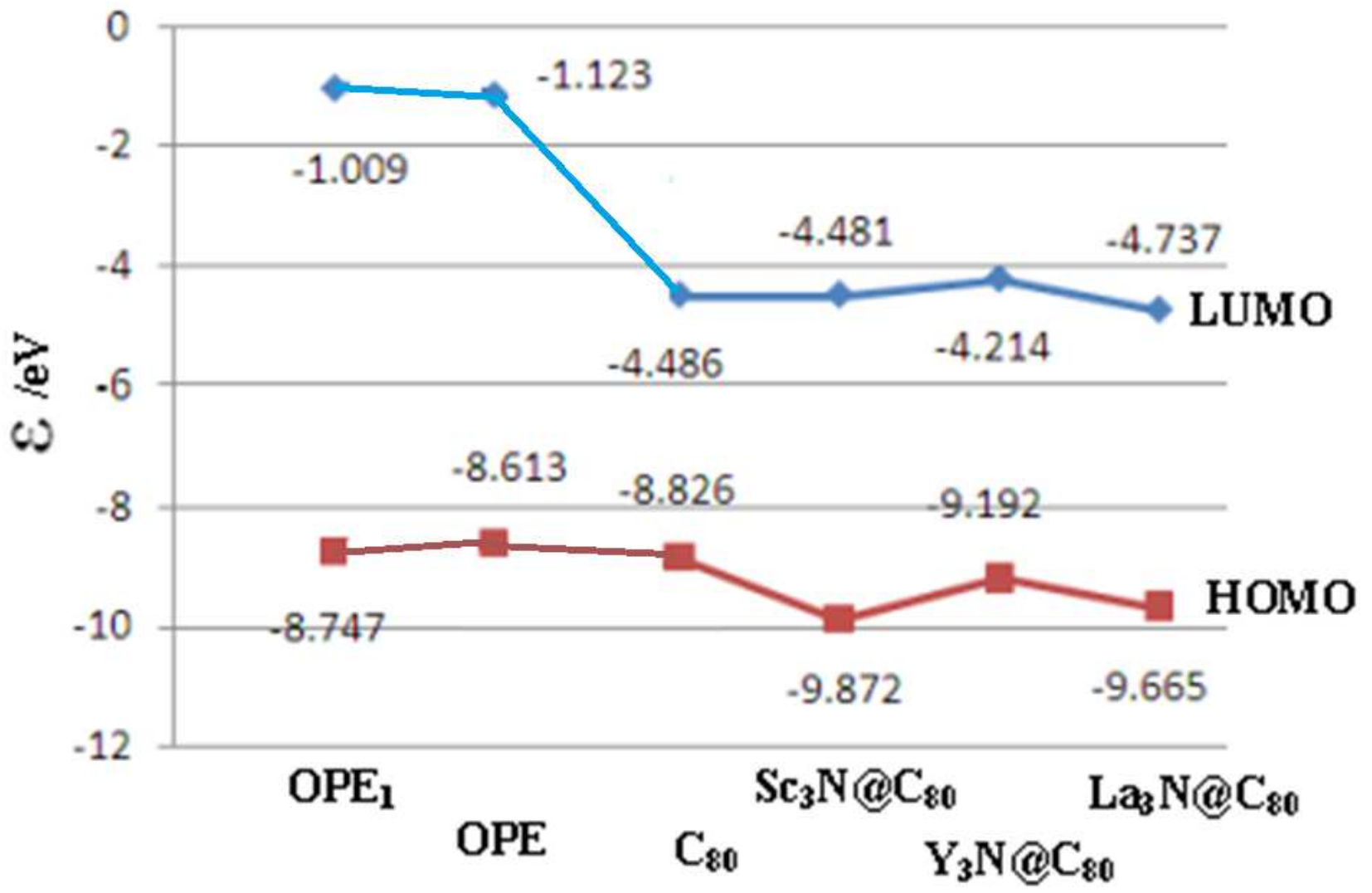

Figure 6. HOMO - LUMO energy levels of subunits of OPE-FDs. 
From Figure 7, it can be seen that OPE has UV absorption, but FDs can interact with visible light or even with NIR. OPE has a long chain of phenylethynyl units, which makes it have more red-shifted peaks than FDs. The peak separation in UV range from $\mathrm{Sc}_{3} \mathrm{~N} @ \mathrm{C}_{80}$ to $\mathrm{La}_{3} \mathrm{~N} @ \mathrm{C}_{80}$ can be explained like that $\mathrm{La}(6 \mathrm{~s}, 6 \mathrm{p}, 5 \mathrm{~d})$ has more diverse interaction with the fullerene cage than $\mathrm{Sc}(4 \mathrm{~s}, 4 \mathrm{p}, 3 \mathrm{~d})$.

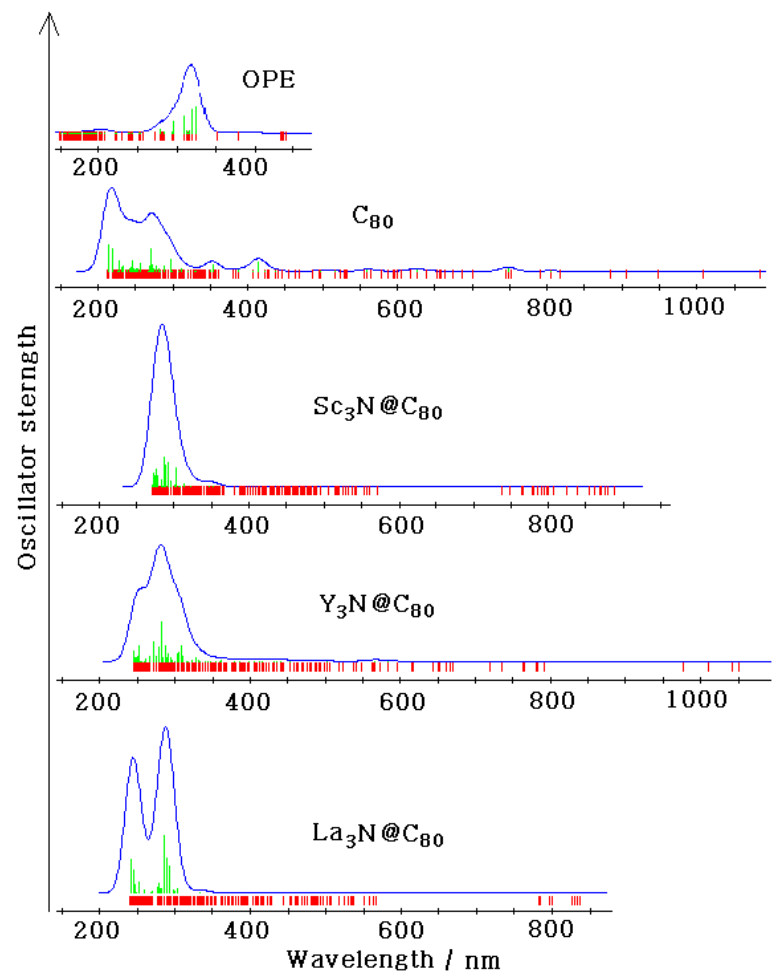

Figure 7. The electronic spectra of OPE and FDs (red: mode positions, green: mode intensities).

2) The geometric and electronic structures of OPE-FDs

Four models of the OPE-FDs discussed in this paper had the similar configurations after geometric optimization (Figure 8).

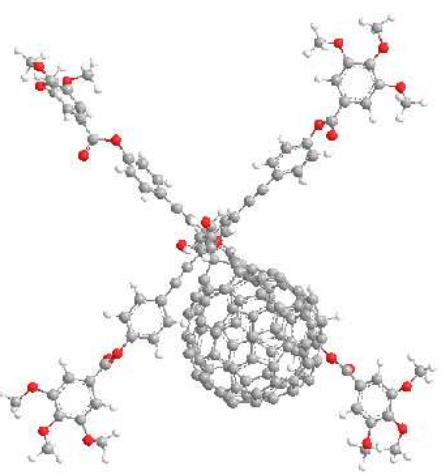

OPE- $\mathrm{C}_{80}$

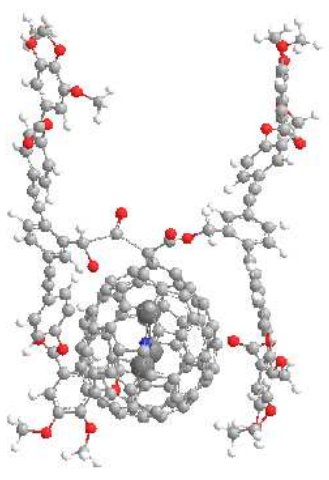

OPE-La $3 \mathrm{~N} @ \mathrm{C}_{80}$
Figure 8. The different views of the optimized structures of OPE-FDs.

These configurations may be different from those of the real OPE-FD dyads [11] because these models have the shorten alkyl group $\left(-\mathrm{CH}_{3}\right)$ instead of the long chain (-
$\mathrm{C}_{12} \mathrm{H}_{25}$ ) and can not express their well-assembled frameworks in the liquid crystalline phase.

Figure 9 shows $\Delta \mathrm{E}_{\mathrm{t}}$ of the OPE-fullerenes calculated as the total energy difference of OPE-FD from its separated subunits (OPE and FD). OPE- $\mathrm{C}_{80}$ became to be unstable after the formation of the dyad and it can be considered as the result of structural deformation of the subunits, especially $\mathrm{C}_{80}$ due to the formation of the dyad. The most stable one was OPE-La $\mathrm{N} @ \mathrm{C}_{80}$ and other OPE-RE $\mathrm{R}_{3} \mathrm{~N} @ \mathrm{C}_{80}$ were also more stable than OPE- $\mathrm{C}_{80}$ because all of $\mathrm{RE}_{3} \mathrm{~N} @ \mathrm{C}_{80}$ had been stabilized by electron transfer from $\mathrm{RE}_{3} \mathrm{~N}$ to $\mathrm{C}_{80}$.

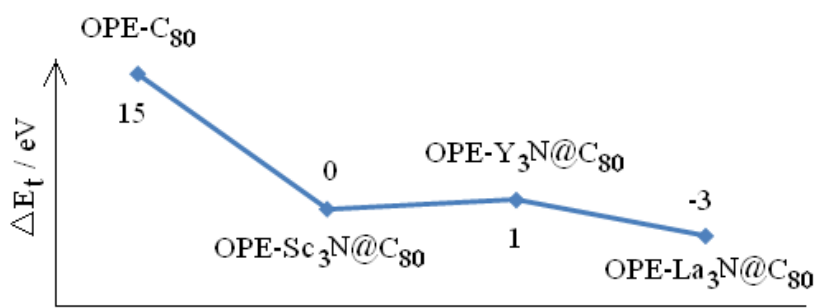

Figure 9. Relative stability $\left(\triangle E_{t}\right)$ of $O P E-F D$ s.

In all of OPE-FDs, the fullerene cages were modified to have the open-up cage (fulleroid) structures. Table 1 shows the $\mathrm{C}$-C distances at the $[6,6]$ OPE-addition sites of FDs and their increases $\left(\triangle \mathrm{R}_{\mathrm{C}-\mathrm{C}}\right)$ after OPE-addition, where more stable OPE-La $\mathrm{L}_{3} \mathrm{~N} @ \mathrm{C}_{80}$ had the less $\Delta \mathrm{R}_{\mathrm{C}-\mathrm{C}}$ and less stable OPE- $\mathrm{C}_{80}$ and $\mathrm{OPE}-\mathrm{Y}_{3} \mathrm{~N} @ \mathrm{C}_{80}$ had the larger $\triangle \mathrm{R}_{\mathrm{C}-\mathrm{C}}$.

Table 1. $C$-C distance at the $[6,6]$ addition site of FDs (nm).

\begin{tabular}{lllll}
\hline model & \multirow{2}{*}{ OPE-C $\mathbf{~}_{\mathbf{8 0}}$} & $\begin{array}{l}\text { OPE- } \\
\mathbf{S c}_{\mathbf{3}} \mathbf{N} @ \mathbf{C}_{\mathbf{8 0}}\end{array}$ & $\begin{array}{l}\text { OPE- } \\
\mathbf{Y}_{\mathbf{3}} \mathbf{N} @ \mathbf{C}_{\mathbf{8 0}}\end{array}$ & $\begin{array}{l}\text { OPE- } \\
\mathbf{L a}_{\mathbf{3}} \mathbf{N} @ \mathbf{C}_{\mathbf{8 0}}\end{array}$ \\
\hline free FD & 0.142 & 0.148 & 0.153 & 0.149 \\
$\mathrm{OPE}-\mathrm{FD}$ & 0.235 & 0.239 & 0.247 & 0.234 \\
$\Delta \mathrm{R}_{\mathrm{C}-\mathrm{C}}$ & 0.093 & 0.091 & 0.094 & 0.085 \\
\hline
\end{tabular}

Table 2 shows the local charges of the subunits (OPE, $\mathrm{C}_{80}$ cage, $\mathrm{RE}_{3} \mathrm{~N}$ ) in OPE-FDs, where there was no considerable charge transfer between OPE and FDs, but in OPE$\mathrm{RE}_{3} \mathrm{~N} @ \mathrm{C}_{80}$ the fullerene cages had the remarkable minus charges mainly due to the electron transfer from $\mathrm{RE}_{3} \mathrm{~N}$ to the cage. It seems that the more electrons were transferred from $\mathrm{RE}_{3} \mathrm{~N}$ to $\mathrm{C}_{80}$, the more stable OPE-RE $\mathrm{N} \mathrm{N} @ \mathrm{C}_{80}$ was formed.

Table 2. Local charges of the subunits in OPE-FDs (e).

\begin{tabular}{lllll}
\hline \multirow{2}{*}{ model } & $\begin{array}{l}\text { OPE- } \\
\mathbf{C}_{\mathbf{8 0}}\end{array}$ & $\begin{array}{l}\text { OPE- } \\
\mathbf{S c}_{\mathbf{3}} \mathbf{N} @ \mathbf{C}_{\mathbf{8 0}}\end{array}$ & $\begin{array}{l}\text { OPE- } \\
\mathbf{Y}_{\mathbf{3}} \mathbf{N} @ \mathbf{C}_{\mathbf{8 0}}\end{array}$ & $\begin{array}{l}\text { OPE- } \\
\mathbf{L a}_{3} \mathbf{N} @ \mathbf{C}_{\mathbf{8 0}}\end{array}$ \\
\hline $\mathrm{OPE}$ & 0.012 & 0.071 & 0.037 & 0.069 \\
$\mathrm{C}_{80}$ cage & -0.012 & -4.454 & -3.976 & -4.471 \\
$\mathrm{RE}_{3} \mathrm{~N}$ & - & 4.383 & 3.939 & 4.402 \\
\hline
\end{tabular}

From the electronic spectra of OPE-FDs (Figure 10), it can be found out that light absorption band of OPE- $\mathrm{C}_{80}$ was more red-shifted than that of OPE- $\mathrm{RE}_{3} \mathrm{~N} @ \mathrm{C}_{80}$, but its maximum absorption intensity was far less than OPE-RE $3 \mathrm{~N} @ \mathrm{C}_{80}$, and all of OPE-FDs seem to have a couple of Vis-NIR absorption peaks. 


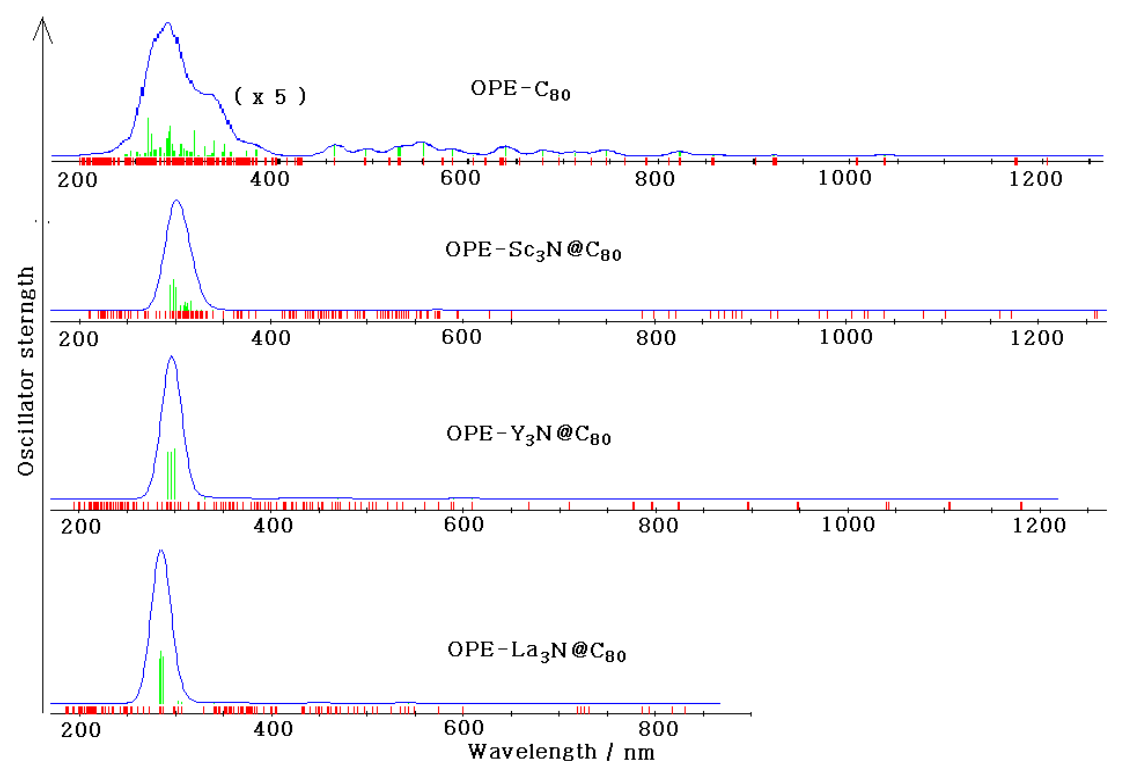

Figure 10. The electronic spectra of OPE-FDs (red: mode positions, green: mode intensities).

The red-shifted band of OPE- $\mathrm{C}_{80}$ compared with OPE$\mathrm{RE}_{3} \mathrm{~N} @ \mathrm{C}_{80}$ can be considered as a result of larger bandgap between HOMO and LUMO: in case of OPE- $\mathrm{C}_{80}$ it was $3.742 \mathrm{eV}$, but OPE-La $\mathrm{N} @ \mathrm{C}_{80}$ has $4.444 \mathrm{eV}$. Moreover, In OPE- $\mathrm{C}_{80}$ both of HOMO and LUMO were located on the fullerene cage, but in OPE-La $\mathrm{N} @ \mathrm{C}_{80} \mathrm{HOMO}$ was on the cage and LUMO was fixed on $\mathrm{La}_{3} \mathrm{~N}$, which means the mechanisms of the electronic excitation in $\mathrm{OPE}-\mathrm{C}_{80}$ and $\mathrm{OPE}-\mathrm{RE}_{3} \mathrm{~N} @ \mathrm{C}_{80}$ can be different. (Figure 11, 12)

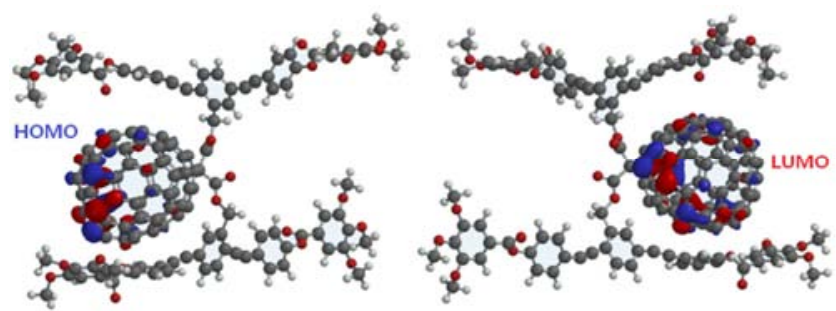

Figure 11. Location of HOMO and LUMO in OPE- $C_{80}$.

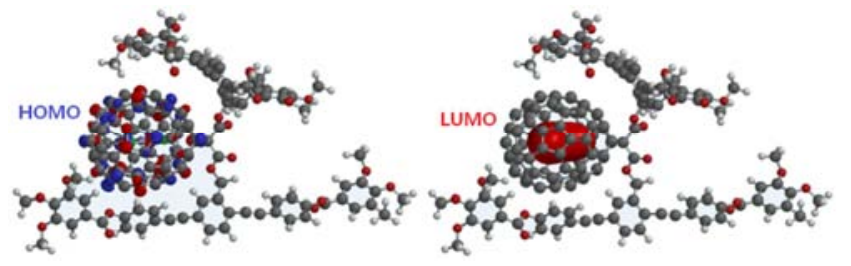

Figure 12. Location of HOMO and LUMO in OPE-La3B@C 80 .

\section{Conclusion}

PM7 calculations were carried out on four OPE-fullerene dyads (OPE-FDs) such as OPE- $\mathrm{C}_{80}$ and $\mathrm{OPE}-\mathrm{RE}_{3} \mathrm{~N} @ \mathrm{C}_{80}(\mathrm{RE}$ $=\mathrm{Sc}, \mathrm{Y}, \mathrm{La})$.

In all of OPE-FDs, the fullerene cages were modified to have the open-up cage (fulleroid) structure by addition of OPE on the $[6,6]$ position of the fullerene cages. The $\mathrm{C}-\mathrm{C}$ distance at the $[6,6]$ addition site of the cages was less increased in the more stable OPE-FDs.

There was no considerable charge transfer between OPE and FDs, but in OPE-RE $3 \mathrm{~N} @ \mathrm{C}_{80}$ the fullerene cages had the remarkable minus charges mainly due to the electron transfer from $\mathrm{RE}_{3} \mathrm{~N}$ to the cage.

Light absorption bands of OPE- $\mathrm{C}_{80}$ were more red-shifted than that of OPE-RE $\mathrm{N}_{3} \mathrm{~N} @ \mathrm{C}_{80}$ and all of OPE-FDs seem to have a couple of Vis-NIR absorption peaks.

\section{Acknowledgements}

The authors thank Stewart Computational Chemistry for its efficient MOPAC2016.

\section{References}

[1] Shiv Bhadra Singh, Aaditya Singh, Int.J. ChemTech Res., 2013, 5, 167-171.

[2] Koichi Komatsu, Phil. Trans. R. Soc. A, 2013, 371, 20110636.

[3] Rajashree Hirlekar, Sushant Gurav, Int. J. Res. Rev. Pharm. Appl. Sci., 2013, 3,351-369.

[4] Peter Nirmalraj, Andrea La Rosa, Damien Thompson, Marilyne Sousa, Nazario Martin, Bernd Gotsmann, Heike Riel, Sci. Rep., 6, 19009; DOI: 10.1038/srep19009 (2016).

[5] Silvia Osuna, Marcel Swart, and Miquel Sola, Phys. Chem. Chem. Phys., 2011, 13, 3585-3603.

[6] Zhiyong Wang, Noriko Izumi, Yusuke Nakanishi, Takeshi Koyama, Toshiki Sugai, Masayoshi Tange, Toshiya Okazaki, Hisanori Shinohara, ACS Nano, 2016, 10, 4282-4287.

[7] Christopher Scott Berger, John W. Marks, Robert D. Bolskar, Michael G. Rosenblum, and Lon J. Wilson, Translational Oncology, 2011, 4, 350-354. 
[8] Jie Meng, Dong-liang Wang, Paul C. Wang, Lee Jia, Chunying Chen, and Xing-Jie Liang, J. Nanosci. Nanotechnol., 2010, 10, 1-7.

[9] Ting Cai, Liaosa Xu, Chunying Shu, Hunter A. Champion, Jonathan E. Reid, Clemens Anklin, Mark R. Anderson, Harry W. Gibson, and Harry C. Dorn, J. Am. Chem. Soc., 2008, 130, 2136-2137.

[10] Michael D. Shultz, James C. Duchamp, John D. Wilson, Chun-Ying Shu, Jiechao Ge, Jianyuan Zhang, Harry W. Gibson, Helen L. Fillmore, Jerry I. Hirsch, Harry C. Dorn, and Panos P. Fatouros, J. Am. Chem. Soc., 2010, 132, 4980-4981.

[11] Kalman Toth, “(Endo) Fullerene functionalization:from material science to biomedical applications" (PhD dissertation), Univ. Strasbourg, 2012, 1-247.

[12] James J. P. Stewart, MOPAC2016, Version: 16.146W, Stewart Computational Chemistry, web: HTTP://OpenMOPAC.net.

[13] A. V. Krisilov, I. V. Nechaev, A. L. Kotova, Kh. S. Shikhaliev, V. E. Chernov, B. A. Zon, Computational and Theoretical Chemistry, 2015, 1054, 100-108.
[14] James J. P. Stewart, J. Mol. Model., 2013, 19, 1-32.

[15] Dutra, J. D. L., Bispo, T. D., Freire, R. O., J. Comput. Chem., 2014, 35, 772-775.

[16] M. de Andrade, Ageo; Camilo Junior, Alexandre; R. de Lazaro, Sergio, Current Physical Chemistry, 2016, 6, 96-104.

[17] Tai-Shan Wang, Lai Feng, Jing-Yi Wu, Wei Xu, Jun-Feng Xiang, Kai Tan, Yi-Han Ma, Jun-Peng Zheng, Li Jiang, Xin Lu, Chun-Ying Shu, and Chun-Ru Wang, J. Am. Chem. Soc., 2010, 132, 16362-16364.

[18] Silvia Osuna, Marcel Swart, and Miquel Sola, J. Am. Chem. Soc., 2009, 131, 129-139.

[19] Stevenson, S., Phillips, J. P., Reid, J. E., Olmstead, M. M., Rath, S. P., and Balch, A. L., Chem. Commun., 2004, 28142815 .

[20] Lothar Dunsch, Shangfeng Yang, Lin Zhang, Anna Svitova, Steffen Oswald, and Alexey A. Popov, J. Am. Chem. Soc., 2010, 132, 5413-5421. 